\title{
Comorbidities in children with Down syndrome: experience in a tertiary care hospital of Bangladesh Zabeen $\mathrm{F}^{\mathrm{a}}$, Mohsin $\mathrm{F}^{\mathrm{b}}$, Jesmin $\mathrm{E}^{\mathrm{c}}$, Mahbuba $\mathrm{S}^{\mathrm{d}}$, Hassan $\mathrm{MQ}^{\mathrm{e}}$
}

\begin{abstract}
Background: Down syndrome or trisomy 21 is one of the most common chromosomal disorders with moderate intellectual disability. In addition to mental retardation, this syndrome is associated with different congenital anomalies and characteristic dysmorphic features. Affected individuals are more susceptible to congenital heart disease and digestive anomalies, pulmonary complications, immune and endocrine system disorders. While several international studies have shown association of co-morbidities with trisomy 21, there is insufficient data available in Bangladesh.The present study aimed to evaluate the associated co-morbidities in children with Down syndrome.

Methods: A cross-sectional study was conducted among pediatric cases with Down syndrome who attended the endocrine outpatient department (OPD) of BIRDEM General Hospital from June 2006 to December 2016. The cases were diagnosed either by Karyotyping or by characteristic phenotypes. The clinical and laboratory data of the patients were collected from outpatient history records for analysis.

Results: There were total 42 children with Down syndrome, with mean age 4.2 years at assessment and female predominance (1.47:1). Thyroid dysfunction was the most common (69\%) followed by congenital heart disease (57\%). Among the thyroid disorders, acquired hypothyroidism was found in 55\% cases, congenital hypothyroidism in $41 \%$ cases and only one had hyperthyroidism. Isolated patent ductus arteriosus (PDA) and atrial septal defect (ASD) comprised the commonest single congenital heart disease found in 53\% and combined atrioventricular septal defect was the commonest among complex congenital cardiac defect observed in our study. Both thyroid dysfunction and congenital heart disease were found more in female children with Down syndrome than their male counterpart and it was found statistically significant. Fifty percent of our Down syndrome cases were referred from other healthcare centers to address developmental delay.

Conclusion: Hypothyroidism and congenital heart disease are frequently associated in Down syndrome children in Bangladesh. This calls for developing awareness among health professionals to diagnose comorbidities at an early stage and to form recommendations for long term follow up.
\end{abstract}

Key words: Congenital heart disease, Down syndrome, trisomy 21, thyroid dysfunction.

(BIRDEM Med J 2021; 11(3): 191-196)

\section{Author information}

a. Fahmida Zabeen, Consultant, Department of Pediatrics and Neonatology, Evercare Hospital, Dhaka, Bangladesh.

b. Fauzia Mohsin, Professor\& Head, Pediatric Endocrinology Unit, Department of Pediatrics, BIRDEM General Hospital, Dhaka, Bangladesh.

c. Eva Jesmin, Consultant, Department of Pediatrics, Combined Military Hospital, Dhaka, Bangladesh.

d. Sharmin Mahbuba, Assistant Professor, Pediatric Endocrinology, Dr. M R Khan Shishu Hospital and Institute of Child Health, Dhaka, Bangladesh.

e. M Quamrul Hassan, Senior Consultant, Dept. of Pediatrics \& Neonatology, Evercare Hospital, Dhaka, Bangladesh.

Address of correspondence: Fahmida Zabeen, Consultant, Department of Pediatrics and Neonatology, Evercare Hospital, Dhaka, Bangladesh. Email: fahmida.zabeen@ hotmail.com

Received: January 30, 2021

Revision received: February 19, 2021

Accepted: June 30, 2021

\section{INTRODUCTION}

Down syndrome or trisomy 21 is the most frequent live born chromosomal aneuploidy in humans and is the most common genetic cause of mild to moderate intellectual disability. ${ }^{1-3}$ The frequency is about 1 in 800 live births each year. ${ }^{4}$ Aside from mental retardation, individuals with Down syndrome usually have physical growth delays and encounter numerous additional health complications including congenital heart disease and gastrointestinal defects, hypothyroidism, respiratory infections and celiac disease. ${ }^{5-9}$

The most common endocrine abnormality in patients with Down syndrome is thyroid dysfunction occurring in $20-50 \%$ cases of various categories like subclinical hypothyroidism $(\mathrm{SCH})$, congenital hypothyroidism $(\mathrm{CH})$ 
and thyroid autoimmunity such as Hashimoto's disease (HD) or Grave's disease (GD). ${ }^{7,10,11}$ Hypothyroidism in patients with Down syndrome can be either congenital or acquired at any age after birth. ${ }^{12,13}$ Type 1 diabetes mellitus is also more common in individual with Down syndrome. ${ }^{7}$ Down syndrome is also frequently associated with congenital heart disease that is observed in up to $50 \%$ of the patients, which are highly relevant to their morbidity and infant mortality. ${ }^{14}$ Trisomy 21 cases are also associated with gastrointestinal anomalies, weak neuromuscular tone, characteristic dysmorphic facial and physical features of the head, neck and airways, audio-vestibular and visual impairment and a higher incidence of other medical disorders. ${ }^{4,15} \mathrm{In}$ addition, there is a significant risk of hearing loss, obstructive sleep apnea and otitis media in Down syndrome cases. ${ }^{10}$ Children with Down syndrome also have lower birth weights and their growth rate is slower than cases without Down syndrome. ${ }^{15}$ Regular systematic screening for health problems in trisomy 21 is recommended throughout their life. ${ }^{16}$ The purpose of this study was to evaluate the associated comorbidities with Down syndrome.

\section{METHODS}

A cross-sectional study was conducted among all children with Down syndrome who attended endocrine outpatient department of BIRDEM General Hospital, from June 2006 to December 2016. They were diagnosed as having Down syndrome either by Karyotyping or by characteristic phenotypes. All the clinical information and laboratory data from outpatient history sheet were collected for analysis and evaluation for accompanying morbidities.Also the initial reason for referral, anthropometric data of patients and maternal age during conception were noted.

\section{Statistical analysis}

Data were analyzed using SPSS 22.0 and OpenEpi, version 3.01. Descriptive analysis was done by computing proportion of categorical variables and mean with standard deviation (SD) for continuous variables. Associations between variables were analyzed by computing $\chi^{2}$ with $p$ value. with $95 \%$ confidence interval (CI).

\section{RESULTS}

Total patients were 42 with female predominance (25) and female to male ratio was $1.47: 1$; there were 33 referral cases. Twenty three (55\%) cases were diagnosed with characteristic phenotype and 19 (45\%) by Karyotyping, of which 20 were trisomy 21 and one had translocation.

The mean age was 4.2 (range 15 days to 16 years) years and median age was 2.4 years. Twenty ( $48 \%$ ) children belonged to 1 to 7 years age group, 14 (33\%) were under 1 year age group and eight (19\%) were between 7 and 16 years of age (Figure 1).

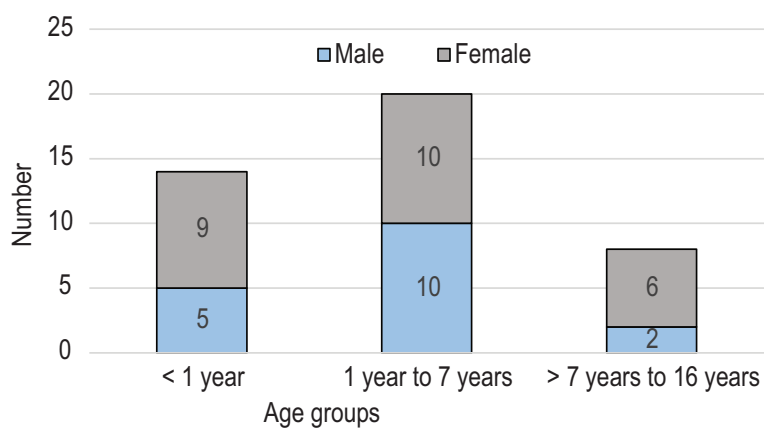

Figure 1 Number of children with Down syndrome by age and gender

Developmental delay, either motor or speech or both was the leading $(50 \%)$ cause for referral, followed by characteristic facial features consistent with Down syndrome (23\%). It was observed that weight for age (at presentation) of $30 \%$ of female children with Down syndrome fell under 5 th percentile, with 16\% (7) being less than 3 SD, while 13\% (5) male with Down syndrome were below $3 \mathrm{SD}$ as per growth charts for children with Down syndrome. ${ }^{16}$ Three females were obese and 1 male was overweight as per Centers for Disease Control and Prevention body mass index (BMI) growth charts. These obese children also had dyslipidemia. Maternal age during conception ranged from 20 to 40 years with mean age 31.2 years.

Thyroid dysfunction $(29,69 \%)$ was the commonest endocrine problem and congenital heart disease was the second most common associated morbidity $(15 / 26$, $57 \%$ ) (echocardiogram was done in 26). Other medical conditions were type 1 diabetes mellitus (2), 4 children had micropenis, of which one child received testosterone and 2 had adrenal insufficiency (one was iatrogenic). Two cases with trisomy 21 had chronic suppurative otitis media with effusion and hearing impairment and one each case of psoriasis, alopecia areata, chronic kidney disease (CKD) and benign sacrococcygeal teratoma (operated at 3 months age). 
Most patients had more than 1 system involvement. Out of 42 children, 28 (57\%) were referred to child developmental center (CDC) and among them 11 (26\%) cases to physiotherapist.

Acquired hypothyroidism was more common (16/29, $55 \%$ ) (10 had subclinical hypothyroidism and two had autoimmune hypothyroidism) and twelve (12/29, 41\%) cases were diagnosed as congenital hypothyroidism (Figure 2). Six cases with congenital hypothyroidism were diagnosed and got treatment with levothyroxine before 2 months age, five cases between 2 months to 8 months and one at the age of 3 years. This 3 years old untreated congenital hypothyroid case presented with precocious puberty with per vaginal bleeding (Van-WykGrumbach syndrome) and had very high TSH ( $>100 \mu \mathrm{IU} /$ ml, normal: $0.47-5)$ and low FT4 (5.15 pmol/L, normal : 9.14 - 23.4). One of the Down cases had transient neonatal hypothyroidism. In our study, only one female patient had hyperthyroidism (Grave's disease), presented with enlarged thyroid gland, increased appetite, hot feeling and loose motion. She had very low TSH: $<0.02 \mu \mathrm{IU} / \mathrm{ml}$ (normal: 0.7-5.7), high FT4:5.44 ng/dl (normal: 0.77-2.08) and markedly raised thyroid antibodies (anti TG 219.32 $\mathrm{IU} / \mathrm{ml}$, normal - up to 20 and anti TPO $>1000 \mathrm{IU} / \mathrm{ml}$, normal up to 35$)$.

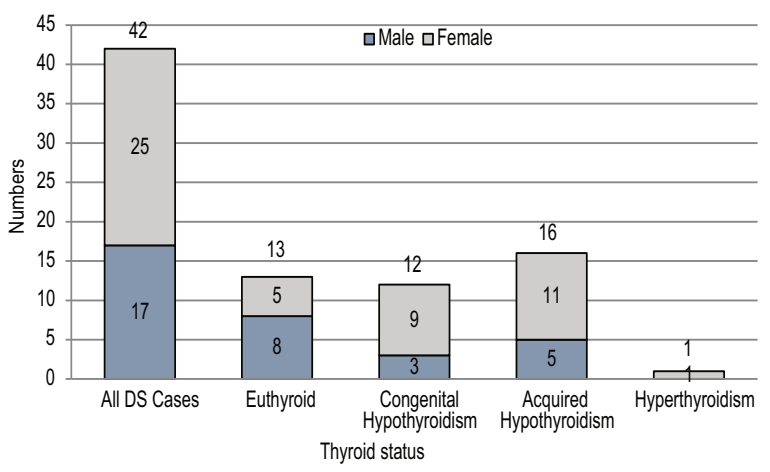

Figure 2 Distribution of thyroid status in Down syndrome cases

Occurrence of hypothyroidism in Down syndrome was associated with female sex [Odds of getting hypothyroidism is 4.2 times than male (95\% CI $1.054-16.74)]$. The relationship was statistically significant $\left(\chi^{2}=4.39\right.$, $\mathrm{p}$ value $=0.036)($ Table I) .

193
Table I Thyroid disorders in Down syndrome children by gender

Sex

$\begin{array}{lll}\text { Thyroid status } & \text { Male Female Total }\end{array}$

Hypothyroidism

Congenital and acquired $\quad \begin{array}{llll}8 & 20 & 28\end{array}$

Euthyroidism

Grave's disease

Transient Neonatal

$\begin{array}{lll}8 & 4 & 12\end{array}$

hypothyroidism

\begin{tabular}{llll}
\hline Total & 16 & 26 & 42 \\
\hline
\end{tabular}

$* \chi^{2}=4.39 \mathrm{p}=0.036$ Odds Ratio $=4.295 \% \mathrm{CI}=1.054-16.74$

Among the congenital heart disease, patent ductus arteriosus (PDA) and secundum type atrial septal defect (ASD) were common, each comprising 4 (27\%) in number followed by 2 cases each with common AV canal defect, large VSD with severe pulmonary hypertension and ASD with VSD and tricuspid regurgitation. One case of congenital mitral regurgitationwas found in echocardiogram finding (Table II).

Table II Types of congenital heart disease found in Down syndrome cases

\begin{tabular}{lcc}
\hline Congenital Heart Disease $(\mathrm{n}=15)$ & Number & $\%$ \\
\hline ASD Secundum & 4 & $27 \%$ \\
Patent Ductus Arteriosus & 4 & $27 \%$ \\
Common AV canal defect & 2 & $13 \%$ \\
Large VSD with Severe Pulmonary & 2 & $13 \%$ \\
Hypertension & & \\
ASD, VSD and Tricuspid Regurgitation & 2 & $13 \%$ \\
Congenital Mitral Regurgitation & 1 & $7 \%$ \\
\hline Total & 15 & $100 \%$ \\
\hline
\end{tabular}

Female Down syndrome children had 6.67 times more chance of getting congenital heart disease than their male counterpart (95\% CI $1.24-35.7)$. The relation is statistically significant $\left(\chi^{2}=3.7, \mathrm{P}=0.029\right)$ (Table III). 
Table III Congenital heart disease found in Down syndrome children

\begin{tabular}{lccc}
\hline & \multicolumn{3}{c}{ Sex } \\
\cline { 2 - 4 } Echo findings & Male & Female & Total \\
\hline Congenital heart disease present & 5 & 10 & $15^{*}$ \\
Normal Echo & 8 & 3 & 11 \\
\hline Total & 13 & 13 & 26 \\
\hline
\end{tabular}

$* \chi^{2}($ Fisher exact $)=$ corrected 3.7, $\mathrm{p}=0.029 \quad$ Odds Ratio $6.67(95 \% \mathrm{CI}=1.24-35.7)$

\section{DISCUSSION}

In this study of children with Down syndrome, we found that, thyroid disorder was the most common and congenital heart disease was the second common associated morbidity. G Annerén et al. reported thyroid dysfunction in 30 out of 85 children (hypothyroidism in 28 and Grave's disease in two) in their observational study among all children, adolescents and young adults under 25 years with Down's syndrome in the county of Uppsala, Sweden. ${ }^{17}$ In a large retrospective study of patients with Down's syndrome, Pierce et al. found 24\% prevalence of thyroid dysfunction, among which subclinical hypothyroidism was most common diagnosis. ${ }^{18}$ Biswas $\mathrm{R}$ et al. also mentioned that $15 \%$ had hypothyroidism and subclinical hypothyroidism was the leading thyroid disorder seen in his study of hospitalized Down children in a tertiary care hospital in Bangladesh. ${ }^{19}$ In our study, we have also observed majority (63\%) of the hypothyroid Down children had subclinical hypothyroidism.

Guaraldi F. et al. and Aversa T. et al. mentioned in their studies that, among autoimmune thyroid dysfunction, autoimmune hypothyroidism or Hashimoto's thyroiditis were more common than hyperthyroidism or Graves' disease. ${ }^{20,21}$ Graber, E. et al. reported in their study that, in $13-34 \%$ patients, thyroid auto antibodies were detected and autoimmune hypothyroidism was usually diagnosed at an earlier age but usually after the age of 8 years. ${ }^{22}$ We have seen 2 cases of autoimmune hypothyroidism and one with Graves' disease in our current study with trisomy 21 . Two of them were above 14 years age and one was 7 years old.

Among 85 patients with Down's syndrome, it was observed that hypothyroidism, compared to hyperthyroidism, is very common where only 2 developed hyperthyroidism. ${ }^{17}$ In our Down syndrome cases, we found only one case of Graves' disease among 29 cases with thyroid disorders. One case of untreated congenital hypothyroidism presented with precocious puberty with per vaginal bleeding, the phenomenon with van-Wyk-Grumbach syndrome. Moreover, patients with Down's syndrome also have a higher prevalence of congenital hypothyroidism with some cases identified on thyroid tests performed within the first 6 months of life that were unidentified on newborn screening. ${ }^{17}$ In Bangladesh, newborn screen is done in a limited health care centers. So, there is even more possibility to miss the cases of congenital hypothyroidism in these children. In our congenital hypothyroid cases with Down syndrome, $50 \%$ were diagnosed before 2 months age and remaining afterwards as late as 3 years age, but none by newborn screening.

A study by the Dutch Paediatric Surveillance Unit (DPSU) of children with Down syndrome revealed that, $43 \%$ of 482 children had CHD. Among those CHD cases, $54 \%$ had atrioventricular septal defect followed by ventricular septal defect (VSD) in 33.3\% and patent ductus arteriosus (PDA) in 5.8\%. ${ }^{23}$ In our current study, we have found congenital heart disease in 15 cases out of 26 , which contributed $57 \%$ in whom echocardiogram was done. We have seen, atrio-ventricular septal defect is one of leading CHD as well as atrial septal defect (ASD) and PDA followed by VSD. In trisomy 21 with congenital heart disease, about $80 \%$ have an atrioventricular septal defect or VSD. ${ }^{7}$ In $40 \%$ cases, we have observed those CHD in our cases with Down syndrome. In another prospective study conducted by Elmagrpy, Z., et al. among 1193 children with Down syndrome at Tripoli, reported $45 \%$ (537) had CHD. It was also found that, majority (65\%) of those children had a single cardiac lesion, whereas the remaining 35\% had multiple defects. ${ }^{24}$ In our Down cases, $73 \%$ had a single cardiac lesion and the rest $27 \%$ had multiple defects.

Nutritional status in the early years is of concern in children with Down syndrome. ${ }^{16}$ Down babies usually encounter feeding difficulties due to hypotonia, poor oromotor and pharyngo-esophageal coordination problem, difficulty initiating sucking, vomiting and choking. ${ }^{25}$ In our study population, anthropometry showed weight for age of $43 \%$ children falls under $5^{\text {th }}$ centile as per growth charts for Down syndrome children. 
On the other hand, children with Down syndrome have an increased risk for obesity. ${ }^{26}$ Previous reports evaluated a prevalence of obesity as high as $30 \%$ to $50 \%,{ }^{27}$ as well as increased adiposity compared with unaffected peers. ${ }^{28}$ There were 3 cases of obesity with dyslipidemia observed in our children with Down syndrome.

Autoimmune disorders are more common in Down syndrome patients compared to the general population. ${ }^{20}$ Other than autoimmune thyroid disease and celiac disease, type 1 diabetes mellitus is three times higher ${ }^{22}$ and alopecia in $11.4 \%{ }^{21}$ There are 2 cases of type 1 diabetes mellitus and one with alopecia areata in our reported cases. Other medical conditions that our reported Down cases encountered are micropenis, adrenal insufficiency, chronic suppurative otitis media, psoriasis, chronic kidney disease and benign sacrococcygeal teratoma. Children with Down syndrome present with delays in motor development. ${ }^{29}$ Fifty percent of our study children were referred cases to address developmental delay in different domains. From endocrine out-patient department (OPD), 28 (67\%) cases attended child developmental center and among those, $11(26 \%)$ cases also required physiotherapy referral.

\section{Conclusion}

Hypothyroidism and congenital heart disease are two most common associated comorbidities in children with Down syndrome in Bangladesh. The clinical resemblance between children with Down syndrome and cases with hypothyroidism often makes it difficult for a physician to detect developing thyroid disease in a child with trisomy 21. Screening for thyroid hormone deficiency at birth and periodically thereafter throughout life is indicated in these children. We also demonstrated other medical conditions contributing morbidies in these children. As there is a different range of co-morbidities observed in the Down syndrome patients, it is important to follow closely for other associated problems. This will help to optimize management plan of these children to ensure best possible care.

Authors' contribution: FZ: Conceptualization, collecting data, literature search andwriting manuscript.

FM: Conceptualization, review and editing, supervision. EJ: Collecting data and literature search.

SM: Collecting data and literature search.

MQH: Review, editing and data analysis.

Conflict of interest: Nothing to declare.

\section{REFERENCES}

1. Patterson D. Molecular genetic analysis of Down syndrome. Human Genetics 2009;126(1): 195-214.

2. Lyle R, Bena F, Gagos S, Gehrig C, Lopez G, Schinzel A, et al. Genotype-phenotype correlations in Down syndrome identified by array CGH in 30 cases of partial trisomy and partial monosomy chromosome 21. Eur J Hum Genet 2009; 17:454-66.

3. Asim A, Kumar A, Muthuswamy S, Jain S, Agarwal S. Down syndrome: an insight of the disease. J Biomed Sci 2015;22:41.

4. Jiang J, Jing Y, Cost GJ, Chiang JC, Kolpa HJ, Cotton AM, et al. Translating dosage compensation to trisomy 21 . Nature 2013;500:296-300.

5. Canfield MA, Honein MA, Yuskiv N, Xing J, Mai CT, Collins JS. National estimates and race/ethnic-specific variation of selected birth defects in the United States, 1999-2001. Birth Defects Res A Clin Mol Teratol 2006 Nov; 76(11):747-56.

6. Weijerman ME, de Winter JP. Clinical practice. The care of children with Down syndrome. European Journal of Pediatrics 2010 Dec; 169 (12): 1445-52.

7. Malt EA, Dahl RC, Haugsand TM, Ulvestad IH, Emilsen NM, Hansen B, et al. Health and disease in adults with Down syndrome. Tidsskr Nor Laegeforen 2013;133: 290-4.

8. Roizen NJ, Patterson D. Down's syndrome. Lancet 2003;361:1281-9.

9. Yang Q, Rasmussen SA, Friedma JM. Mortality associated with Down's syndrome in the USA from 1983 to 1997: a population-based study. Lancet 2002;359:1019-25.

10. Bull MJ. Health supervision for children with Down syndrome. Pediatrics 2011;128 (2):393-406.

11. Amr NH. Thyroid disorders in subjects with Down syndrome: an update. Acta Biomed 2018; 89 (1): 132-9.

12. Prasher V. Prevalence of thyroid dysfunction and autoimmunity in adults with Down syndrome. Down Syndr Res Pract 1994; 2(2): 67-70.

13. Kinnell HG, Gibbs N, Teale JD, Smith J. Thyroid dysfunction in institutionalized Down's syndrome adults. Psychol Med 1987; 17(2): 387-92.

14. Vis JC, Duffels MGJ, Winter MM, Wejjerman ME, Cobben JM, Huisman SA. et al. Down syndrome: a cardiovascular perspective. J Intellect Disabil Res 2009 May; 53 (5):41925 .

15. Hattori M, Fujiyama A, Taylor TD, Watanabe H, Yada T, Park HS, et al. The DNA sequence of human chromosome 21. Nature 2000; 405: 311-9.

16. Zemel BS, Pipan M, Stallings VA, Hall W, Schgadt K, Freedman DS, et al. Growth Charts for Children With 
Down Syndrome in the United States. Pediatrics 2015 Nov;136(5):e1204-11.

17. Karlsson B, Gustafsson J, Hedov G, Ivarsson S, Anneren, G. Thyroid dysfunction in Down syndrome: relation to age and thyroid autoimmunity. Arch Dis Child 1998 Sept; 79(3): 242-5.

18. Pierce MJ, LaFranchi SH, Pinter JD. Characterization of Thyroid Abnormalities in a Large Cohort of Children with Down Syndrome. Horm Res Paediatr 2017;87: $170-8$.

19. Biswas R, Munsi AS, Hussain M, Alam MJ, Ahmed NU. Functional Status of Thyroid Gland in Hospitalized Children With Down's Syndrome. Bangladesh J Child Health 2015; 39(3): 123-8.

20. Guaraldi F, Giaccherino R, Lanfranco F, Motta G, Gori D, Arvat E, et al. Endocrine autoimmunity in Down's syndrome. Horm Res 2017; 48: 133-46.

21. Aversa T, Salerno M, Radetti G, Faienza MF, Iughetti L, Corrias A, et al. Peculiarities of presentation and evolution over time of Hashimoto's thyroiditis in children and adolescents with Down's syndrome. Hormones 2015; 14 : 410-6.

22. Graber E, Chacko E, Regelmann M, Costin G, Rapaport R. Down syndrome and thyroid function. Endocrinol Metab Clin N Am 2012; 41: 735-45.

23. Weijerman ME, van Furth AM, van der Mooren MD, van Weissenbruch MM, Rammeloo L, Broers CJ, et al.
Prevalence of congenital heart defects and persistent pulmonary hypertension of the neonate with Down syndrome. Eur J Pediatr 2010 Oct; 169(10): 1195-9.

24. Elmagrpy Z, Rayani A, Shah A, Habas E, Aburawi EH. Down Syndrome and Congenital Heart Disease: Why the Regional Difference as Observed in the Libyan Experience? Cardiovascular Journal of Africa 2011; 22 (6): 306-9.

25. Lewis E, Kritzinger A. Parental experiences of feeding problems in their infants with Down syndrome. Downs Syndr Res Pract 2004; 9(2):45-52.

26. Hermon C, Alberman E, Beral V, Swerdlow AJ. Mortality and cancer incidence in persons with Down's syndrome, their parents and siblings. Ann Hum Genet 2001; 65(2):167-76.

27. Day SM, Strauss DJ, Shavelle RM, Reynolds RJ. Mortality and causes of death in persons with Down syndrome in California. Dev Med Child Neurol 2005; 47(3): 171-6.

28. Harris N, Rosenberg A, Jangda S, O'Brien K, Gallagher ML. Prevalence of obesity in International Special Olympic athletes as determined by body mass index. J Am Diet Assoc 2003; 103(2): 235-7.

29. Malak R, Kostiukow A, Wasielewska AK, EwaMojs, Samborski W. Delays in motor development in children with Down syndrome. Med Sci Monit 2015; 21: 1904-10. 